TEODORO, A.L. et al. Grão úmido na alimentação animal: estudo metanalítico. PUBVET, Londrina, V. 6, N. 4, Ed. 191, Art. 1283, 2012.

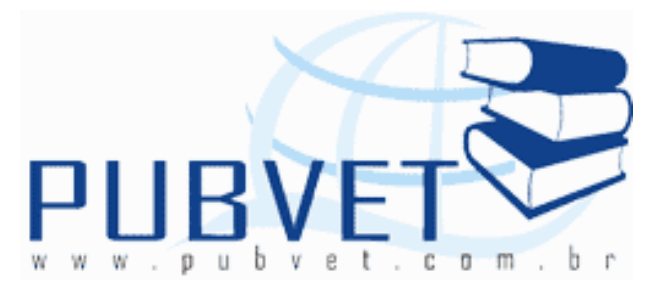

PUBVET, Publicações em Medicina Veterinária e Zootecnia.

\title{
Grão úmido na alimentação animal: estudo metanalítico ${ }^{1}$
}

Ana Lúcia Teodoro²; Fernando Miranda de Vargas Junior ${ }^{3}$; Marcus Vinicius Morais de Oliveira ${ }^{3}$; Maíza Leopodina Longo ${ }^{4}$; João Rufino Junior ${ }^{4}$; Thaís Assad Galharte Figueiredo ${ }^{4}$

${ }^{1}$ Parte de trabalho apresentado a Disciplina de Conservação de Alimentos para a Produção Animal oferecido pelo Programa de Pós Graduação em Zootecnia da UFGD;

${ }^{2}$ Doutoranda em Zootecnia, UEM, Maringá, PR.

Email: analuciazoo@yahoo.com.br;

${ }^{3}$ Faculdade de Ciências Agrárias - UFGD, Dourados, MS.

${ }^{4}$ Mestrandos em Zootecnia, UFGD, Dourados, MS.

\section{Resumo}

O presente trabalho teve como objetivo realizar um estudo metanalítico para analisar os artigos publicados sobre a utilização de silagem grãos úmidos na alimentação animal entre os anos de 2000 e 2011, para tanto pesquisou-se todos os trabalhos publicados nesses anos nas revistas: Revista Brasileira de Zootecnia e Ciência Rural, admitindo-se apenas artigos que tenham tratamento controle e que avaliaram desempenho, característica de carcaça e parâmetros digestivos, com ou sem análise econômica. Os trabalhos foram tabulados em planilhas eletrônicas (Excel) e comparou-se todos os tratamentos com seus respectivos controle, chegando-se a conclusão que o 
TEODORO, A.L. et al. Grão úmido na alimentação animal: estudo metanalítico. PUBVET, Londrina, V. 6, N. 4, Ed. 191, Art. 1283, 2012.

método metanalítico pode ser considerado uma importante ferramenta que permite avaliar as respostas produtivas em experimentos que utilizaram grão úmido na produção animal. Na maioria dos trabalhos analisados obteve-se resultados positivos, ainda que alguns efeitos indiretos não foram mensurados em diversos experimentos.

Palavras-chave: alimentação animal, grão com alta umidade, meta - análise

\section{Moist grain in animal nutrition: meta-analytic study}

\section{Abstract}

The present work had as objective accomplishes a meta-analytic study to analyze the goods published about the use of silage humid grains in the animal feeding between the years 2000 and 2011, for both research gathered all papers published in those years in the magazines: Brazilian magazine of Zootecnia and Rural Science, being just admitted goods to have treatment controls and that evaluated acting, carcass characteristic and digestive parameters, with or without economical analysis. The works were tabulated in electronic spreadsheets (Excel) and it was compared all of the treatments with their respective control, the conclusion that the method meta-analytic can be considered an important tool that allows to evaluate the productive answers in experiments that used humid grain in the animal production being arrived. In most of the analyzed works it was obtained positive results, although some indirect effects were not measured in several experiments.

Keywords: animal feeding, grain with high humidity, meta - analysis

\section{Introdução}

Os grãos em geral são de grande importância na alimentação animal, sendo considerados excelente fonte de energia. Portanto, é importante que o amido presente esteja mais disponível para a digestão e aproveitamento do animal. Essa disponibilidade pode ser melhorada através de processamentos físico-químicos, entre eles a ensilagem dos grãos úmidos. 
TEODORO, A.L. et al. Grão úmido na alimentação animal: estudo metanalítico. PUBVET, Londrina, V. 6, N. 4, Ed. 191, Art. 1283, 2012.

A ensilagem de grãos úmidos pode ser vantajosa em termos agronômicos e nutricionais, seja desocupando a área de plantio mais cedo, já que o grão vai ser colhido antes da secagem, ou ainda melhorando a conversão alimentar com o uso do grão ensilado na alimentação animal. Berndt et al. (2002) afirmam que os ganhos em eficiência alimentar pode ser de cerca de $10 \%$ dependendo da quantidade de grão seco substituído e da umidade e qualidade do grão ensilado.

Henrique et al. (2007) explicam que os resultados a respeito do uso do grão com alta umidade na dieta animal é bastante variável. Sendo assim, uma revisão através de métodos metanalíticos pode ser uma ferramenta importante para se chegar a conclusões a respeito do uso da ensilagem de grão úmido.

De acordo com Lovatto et al. (2007) as revisões tradicionais objetiva extrair informações de trabalhos publicados com ou sem análise estatística que muitas vezes pode não ser adequada, já que esta é dependente do tamanho da amostra. Através da metanálise pode-se ter estimativa imparcial do efeito de tratamento com maior precisão. Com isso a metanálise pode evidenciar o efeito de um tratamento que não permitiu se chegar a uma conclusão em virtude de falta de potência analítica (baixo $n$ ).

Sendo assim este trabalho teve como objetivo realizar um estudo metanalítico para analisar os artigos publicados sobre a utilização de silagem grãos úmidos na alimentação animal entre os anos de 2000 e 2009.

\section{Material e Métodos}

Os artigos utilizados na metanálise foram obtidos de revistas nacionais da área zootécnica através do site www.scielo.br, onde optou-se em esgotar todos os trabalhos que testaram o uso de silagem de grão úmido de diferentes grãos na alimentação animal.

Pesquisou-se todos os artigos publicados entre 2000 e junho de 2011 nas revistas: Revista Brasileira de Zootecnia e Ciência Rural, utilizou-se critérios de seleção para filtrar os trabalhos pesquisados, admitindo-se apenas os trabalhos com animais e que avaliaram desempenho, característica de 
TEODORO, A.L. et al. Grão úmido na alimentação animal: estudo metanalítico. PUBVET, Londrina, V. 6, N. 4, Ed. 191, Art. 1283, 2012.

carcaça e parâmetros digestivos, com ou sem análise econômica, já que a parte econômica foi pouco explorada nos trabalhos de forma geral. Os artigos que não tinham tratamento controle foram excluídos da análise.

Inicialmente identificou-se 46 artigos e destes selecionou-se 22 trabalhos que foram tabulados em planilhas eletrônicas (Excel), totalizando 55 tratamentos diferentes, incluindo controle, envolvendo diferentes espécies e categorias animais. A distribuição entre espécies foi: 11 trabalhos com bovinos (Berndt et al., 2002; Passini et al., 2003; Henrique et al., 2007; Silva et al., 2007; Putrino et al., 2007; Almeida Junior et al., 2008a, Almeida Junior et al., 2008b; Almeida Junior et al., 2008c; Igarasi et al., 2008a; Igarasi et al., 2008b; Almeida Junior et al., 2008d), três com ovinos (Reis et al., 2001; Almeida Junior et al., 2004a; Almeida Junior et al., 2004b) , quatro com suínos (Oliveira et al., 2004; Silva et al., 2005; Patrício et al., 2006; Lovatto et al., 2009), dois com eqüídeos (Santos et al., 2002; Oliveira et al., 2007), um com coelhos (Furlan et al., 2006) e um com aves (Barcellos et al., 2006). Quanto ao grão testado 12 trabalhos foram com grão úmido de milho, 9 com grão úmido de sorgo com e sem tanino e apenas um trabalho com grão de triticale.

A análise dos dados foram feitas através de planilhas eletrônicas (Excel), baseadas em equação adaptada de Zopollatto et al. (2009), sendo ((Valor do tratamento testado - Valor do tratamento controle) X 100) de cada trabalho. Desta forma foi possível obter a variação em porcentagem dos tratamentos testados em relação ao tratamento controle (grão seco), que resultaram em diversos gráficos de dispersão dos dados.

\section{Resultados e Discussão}

Analisando os artigos selecionados sobre grão úmido, observa-se na Figura 1 a distribuição das publicações entre os anos de 2000 e 2011. Em 2008 houve um maior número de trabalhos publicados ( 6 trabalhos) e as variáveis mais medidas de forma geral foram ganho de peso, consumo e conversão alimentar, sendo $14 ; 8$ e 8 trabalhos, respectivamente. A eficiência alimentar foi mencionada apenas em três trabalhos publicados em 2007, que foram 
TEODORO, A.L. et al. Grão úmido na alimentação animal: estudo metanalítico. PUBVET, Londrina, V. 6, N. 4, Ed. 191, Art. 1283, 2012.

Henrique et al. (2007), Silva et al. (2007) e Putrino et al. (2007) os quais trabalharam com bovinos jovens em terminação.

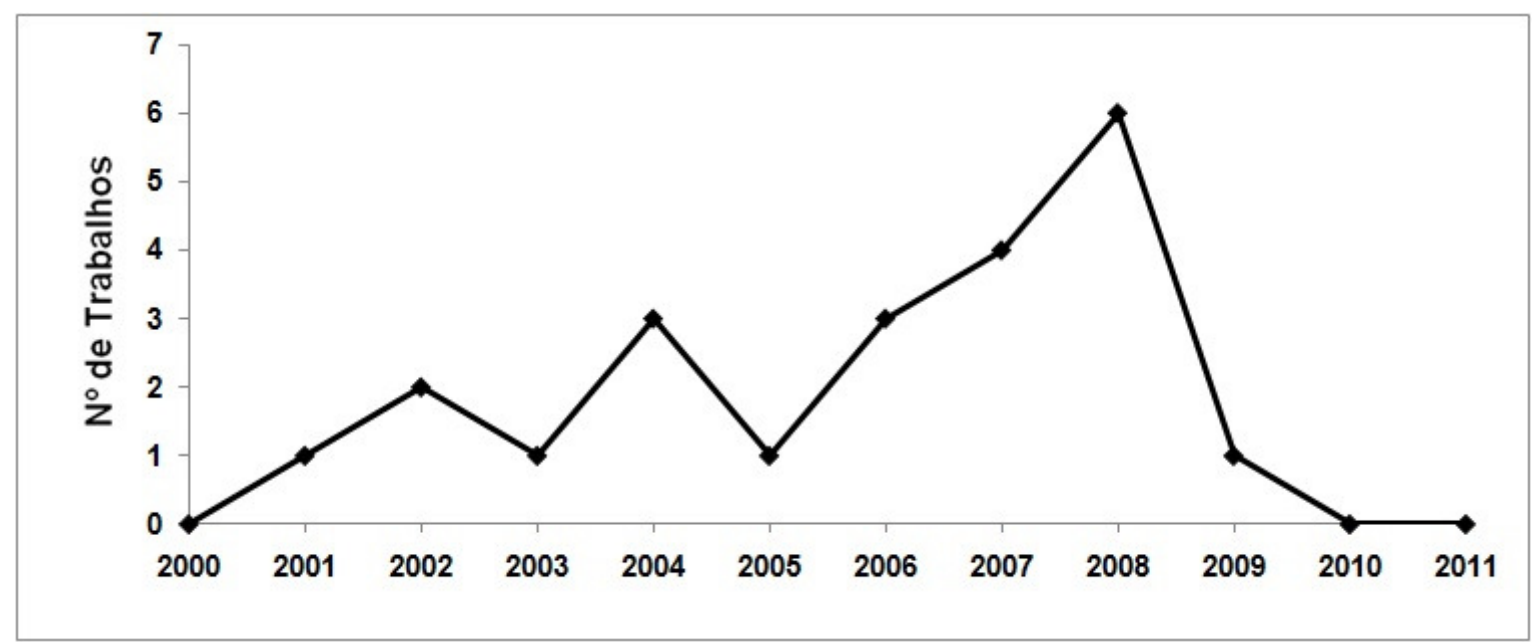

Figura 1: Distribuição dos trabalhos selecionados entre os anos de 2000 e 2011.

Dos 34 tratamentos que foi mensurado consumo pode-se observar (Figura 2) que na maioria dos tratamentos (52,94\%) houve redução do consumo quando utilizado o grão úmido na dieta, independente de ser grão de sorgo ou de milho. Quando se trabalhou com ruminantes houve redução no consumo médio de 0,868 kg MS/dia para bovinos (Henrique et al., 2007; Silva et al., 2007) e 0,05 kg MS/dia para ovinos (Almeida Junior et al., 2004), mas com monogástricos foi bastante variável, com frango de corte (Barcellos et al., 2006) e suínos em terminação (Oliveira et al., 2004) houve redução média de $0,133 \mathrm{~g} \mathrm{MS} /$ dia e 0,056 kg MS/dia, respectivamente. Já com coelhos (Furlan et al., 2006), porcas lactantes ( Lovatto et al., 2009) e leitões (Patrício et al., 2006) aumentou a ingestão da dieta composta por grão úmido, sendo em média 17,85 g MS/dia, 0,46 kg MS/dia e 0,037 kg MS/dia, respectivamente. 0 fato de ser sorgo com e sem tanino ou milho não influenciou o consumo. 
TEODORO, A.L. et al. Grão úmido na alimentação animal: estudo metanalítico. PUBVET, Londrina, V. 6, N. 4, Ed. 191, Art. 1283, 2012.

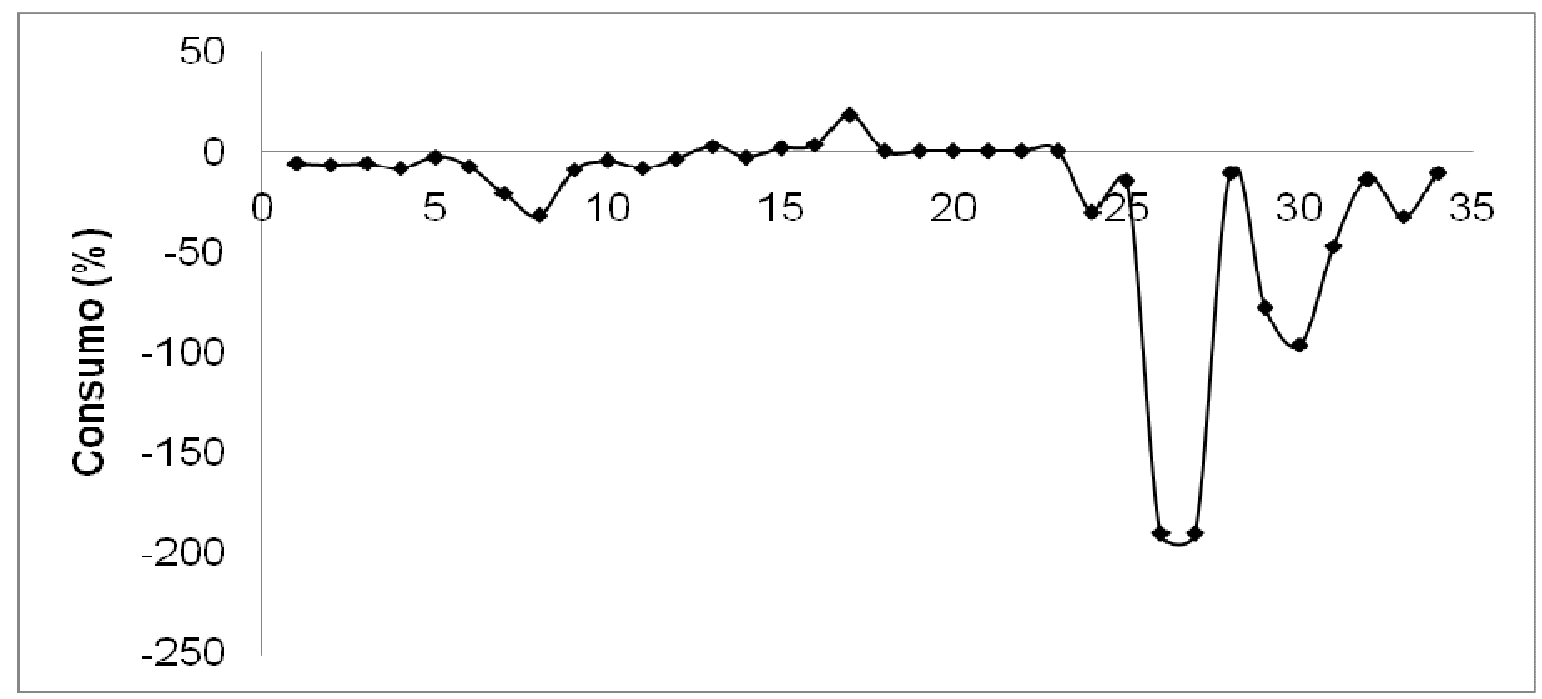

Figura 2: Distribuição do consumo em relação ao tratamento controle de cada experimento.

Para a variável ganho de peso (Figura 3) foram testados 49 tratamentos, destes $63,26 \%$ tiveram efeito positivo, enquanto que apenas 4,09\% foram iguais e $32,65 \%$ negativos, quando comparados aos respectivos tratamentos controle de cada ensaio experimental. Quando se trabalhou com cordeiros (Reis et al., 2001; Almeida Junior et al., 2004) e coelhos (Furlan et al., 2006) o ganho de peso foi sempre positivo, enquanto que com eqüídeo foram todos negativos (Santos et al., 2002) e bastante variável com bovinos (Berndt et al., 2002; Henrique et al., 2007; Silva et al., 2007; Putrino et al., 2007; Almeida Junior et al., 2008; Igarasi et al., 2008a; Igarasi et al., 2008b), frangos de corte (Barcellos et al., 2006) e suínos (Oliveira et al., 2004; Patrício et al., 2006), independente da fase de crescimento dos animais. 
TEODORO, A.L. et al. Grão úmido na alimentação animal: estudo metanalítico. PUBVET, Londrina, V. 6, N. 4, Ed. 191, Art. 1283, 2012.

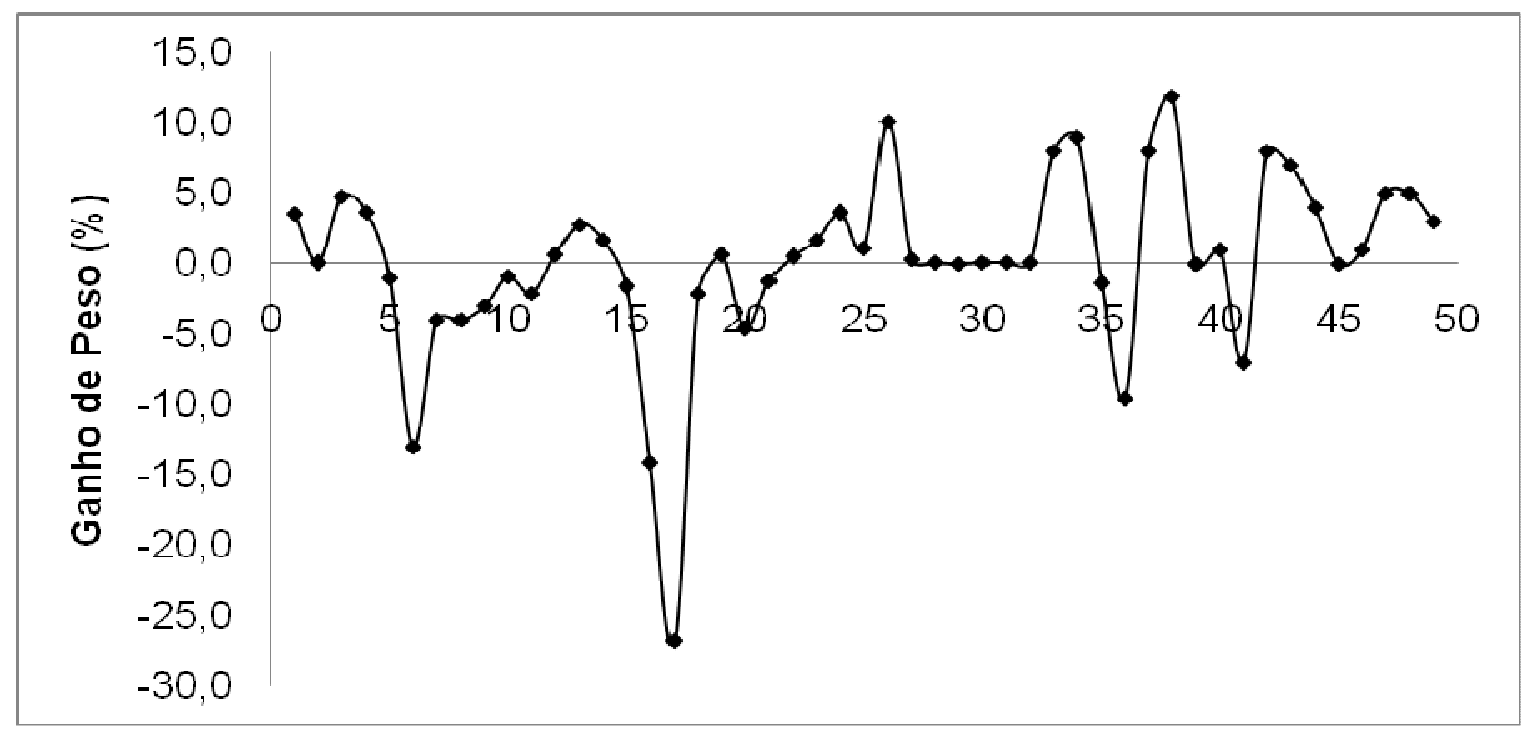

Figura 3: Distribuição do ganho de peso dos tratamentos testados em relação ao tratamento controle.

Apesar do ganho de peso ser nulo ou negativo em alguns experimentos, pode-se nestes casos ainda ter efeitos positivos indiretos que não foram mensurados durante o desenvolvimento da pesquisa, como por exemplo desocupação da área plantada mais cedo, redução dos gastos como armazenagem do grão seco e ainda a vantagem do grão ensilado não sofrer ataques de insetos ou fungos, que podem reduzir a qualidade nutritiva do grão seco.

Quando se discute conversão alimentar é importante que haja redução desta para que a eficiência alimentar seja melhor, ou seja, quanto menos ração for ingerida para que o animal ganhe um quilo de peso vivo ou produza leite ou ovos, melhor a eficiência alimentar deste animal. Em todos os trabalhos analisados verificou-se que oito mediram conversão alimentar e apenas três mediram eficiência alimentar, totalizando 37 e 6 tratamentos, respectivamente. No entanto, os trabalhos que mediram eficiência não mediram conversão alimentar, e vice-versa, já que uma é sinônimo da outra.

$\mathrm{Na}$ maioria dos tratamentos que mediram conversão alimentar (Figura $4), 64,86 \%$ apresentaram melhores resultados enquanto que $32,43 \%$ foram 
TEODORO, A.L. et al. Grão úmido na alimentação animal: estudo metanalítico. PUBVET, Londrina, V. 6, N. 4, Ed. 191, Art. 1283, 2012.

piores e apenas $2,71 \%$ foram iguais em relação aos tratamentos controle. Sendo assim, pode se dizer que a utilização do grão úmido na ração animal melhorou a digestibilidade do grão de forma geral, aumentando o aproveitamento de nutrientes pelos animais. As respostas positivas foram bastante heterogêneas em termos de espécie animal, sendo encontrado resultados diferentes com a mesma espécie e categoria animal independente do uso de sorgo com e sem tanino ou milho.

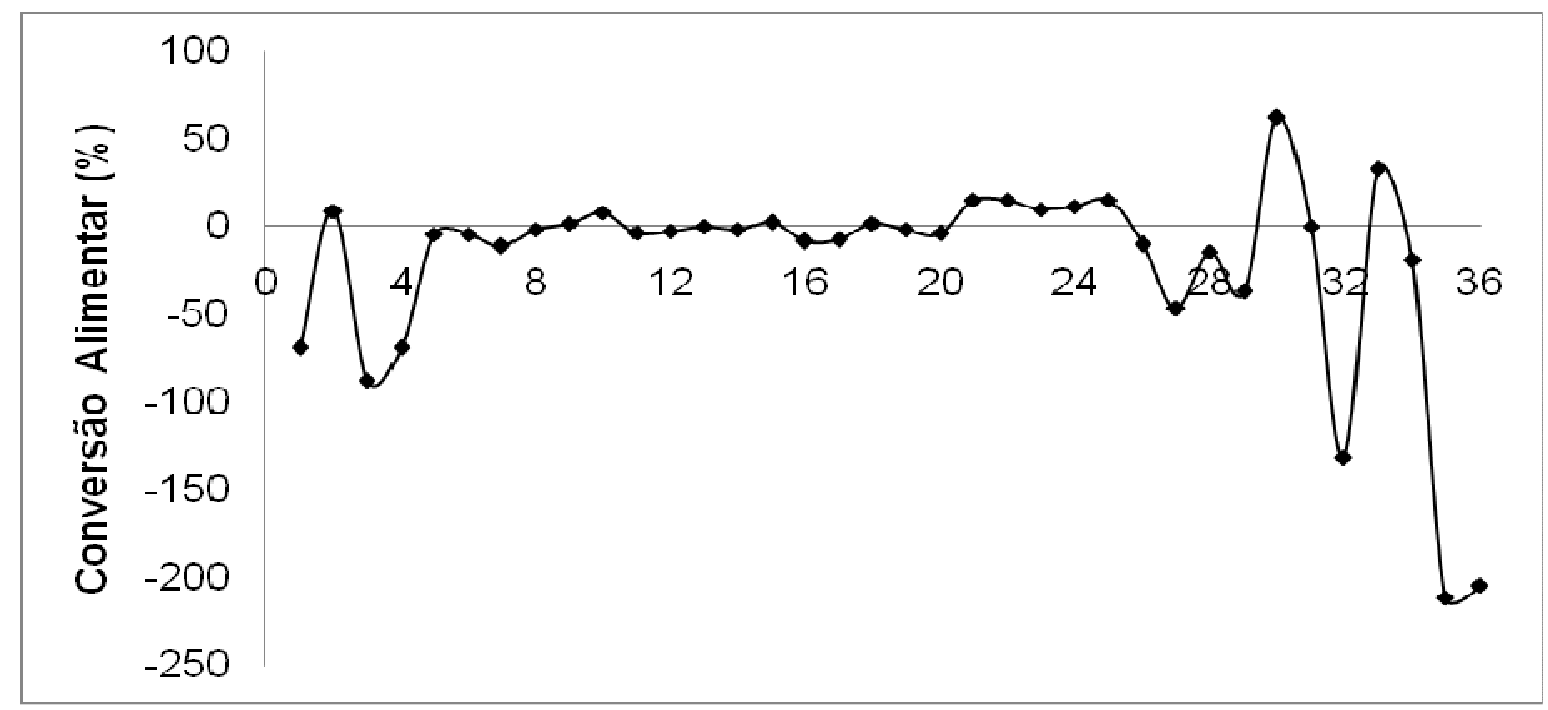

Figura 4: Distribuição da conversão alimentar em relação ao tratamento controle.

Já em relação à eficiência alimentar todos os resultados encontrados foram positivos comparados ao grupo controle, no entanto a variação foi baixa $(<0,04 \%)$ e o $n$ ainda é muito pequeno para que se tenha uma resposta conclusiva a respeito desta variável, considerando que apenas três artigos mediram eficiência alimentar (Henrique et al., 2007; Silva et al., 2007; Putrino et al., 2007) totalizando 6 tratamentos diferentes e esses trabalharam apenas com bovinos, portanto ainda há necessidade de se analisar melhor este parâmetro. 
TEODORO, A.L. et al. Grão úmido na alimentação animal: estudo metanalítico. PUBVET, Londrina, V. 6, N. 4, Ed. 191, Art. 1283, 2012.

Em virtude do baixo número de repetições de alguns índices analisados pelos experimentos não foi possível de se obter uma conclusão nas vaiáveis relacionadas a parâmetros digestivos e características de carcaça, sugerindo-se que a haja melhor padronização das variáveis analisadas nesses parâmetros.

Apenas parte dos trabalhos selecionados apresentava análise econômica do uso da silagem de grão úmido. Dos 22 trabalhos iniciais apenas seis apresentaram os custos das dietas (Oliveira et al., 2004; Almeida Junior et al., 2004; Patrício et al., 2006; Furlan et al., 2006; Almeida Junior et al., 2008a; Almeida Junior et al., 2008b). Quando analisou-se o custo por quilo de ração (Figura 5), de um total de 23 tratamentos, apenas $8,7 \%$ deles foram maiores do que o controle, ou seja, de forma geral o custo do grão úmido foi menor em $91,30 \%$ dos tratamentos, independente do grão usado e da espécie e categoria animal testados no experimento.

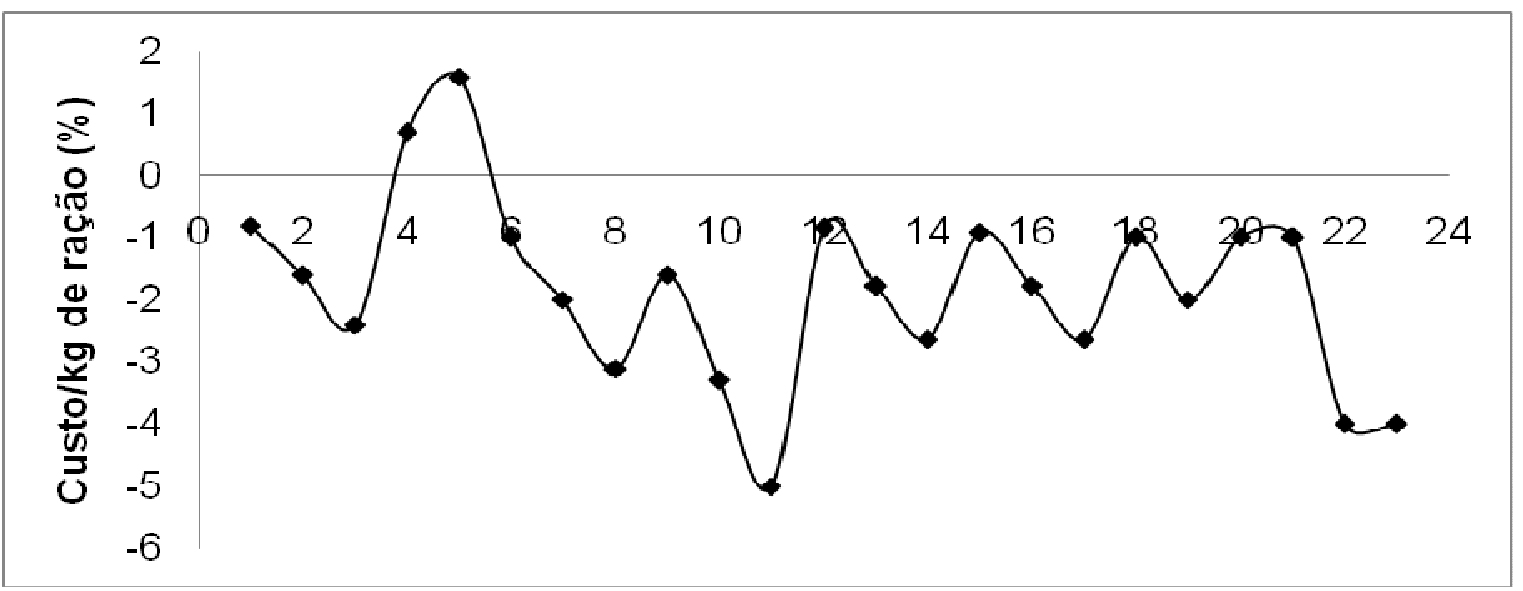

Figura 5: Distribuição dos custos por quilo de ração com uso do grão úmido em relação ao controle dos respectivos experimentos.

Para custo por quilo de ganho de peso, analisou-se cinco trabalhos sendo dois trabalhos com suínos (Oliveira et al., 2004; Patrício et al., 2006), um com coelhos (Furlan et al., 2006) e dois com bovinos (Almeida Junior et al., 2008a; Almeida Junior et al., 2008b) que totalizaram 21 tratamentos e destes 5\% foram maiores e $76,19 \%$ foram menores do que o tratamento controle dos 
TEODORO, A.L. et al. Grão úmido na alimentação animal: estudo metanalítico. PUBVET, Londrina, V. 6, N. 4, Ed. 191, Art. 1283, 2012.

respectivos experimentos (Figura 6), podendo se dizer que o uso do grão úmido nas dietas teve um efeito positivo na variável custo por ganho de peso tanto para ruminantes quanto para monogástricos.

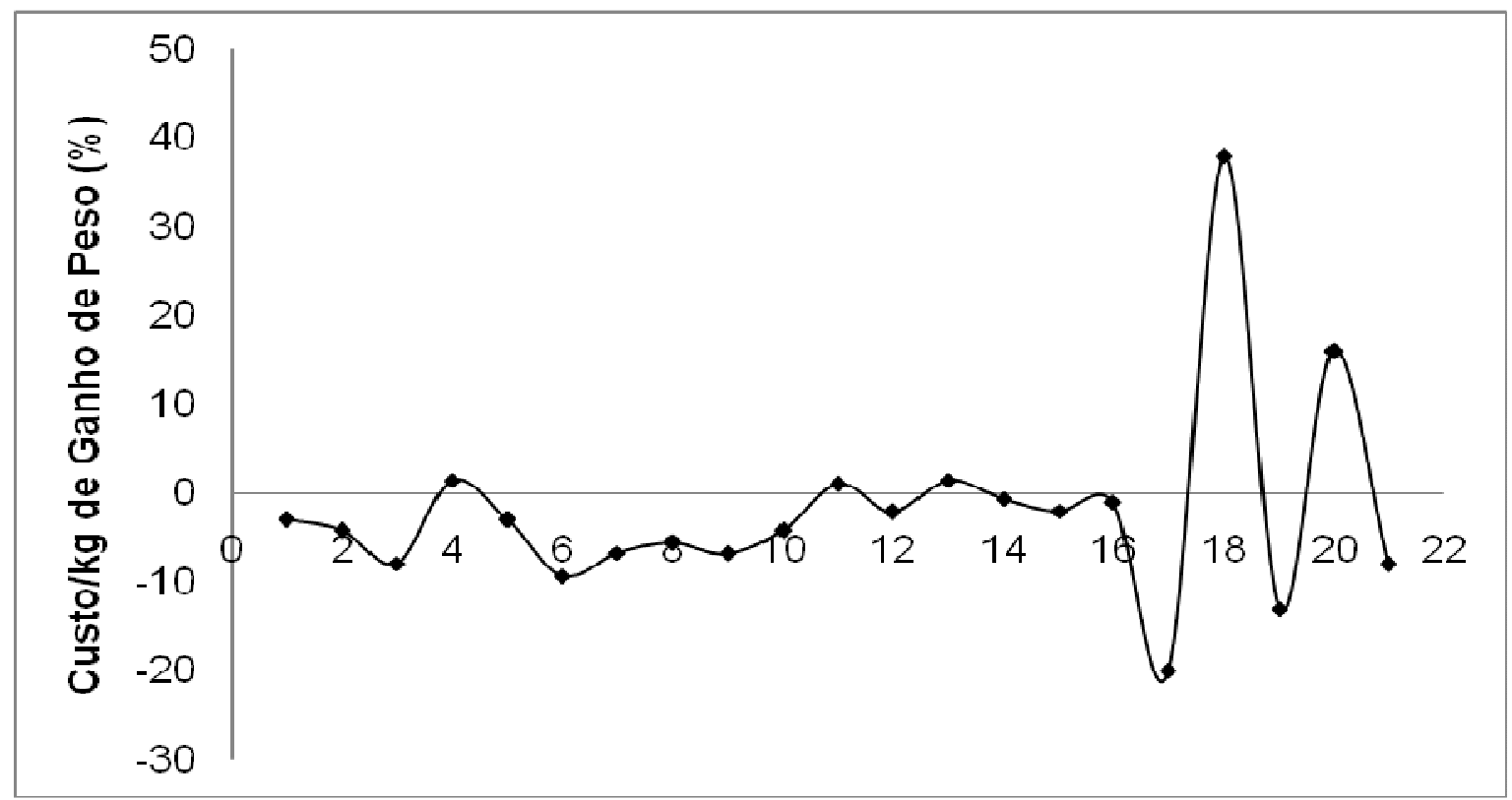

Figura 6: Distribuição dos custos por quilo de ganho de peso de animais alimentados com grão úmido em relação aos tratamentos controle.

A eficiência econômica foi medida em apenas três experimentos que trabalharam com monogástricos e nenhum com ruminantes, sendo um com coelho (Furlan et al., 2006) e dois com suínos (Oliveira et al., 2004; Patrício et al., 2006), que totalizaram 15 tratamentos e a maioria $80 \%$ foram maiores e apenas $20 \%$ menores que os tratamentos controle (Figura 7 ). Os mesmos trabalhos mediram o índice de custo que também foi favorável para os tratamentos que utilizaram o grão úmido na dieta (Figura 8 ), ou seja, $80 \%$ dos tratamentos apresentaram o índice de custo menor e apenas $20 \%$ maiores do que o tratamento controle dos respectivos experimentos. 
TEODORO, A.L. et al. Grão úmido na alimentação animal: estudo metanalítico. PUBVET, Londrina, V. 6, N. 4, Ed. 191, Art. 1283, 2012.

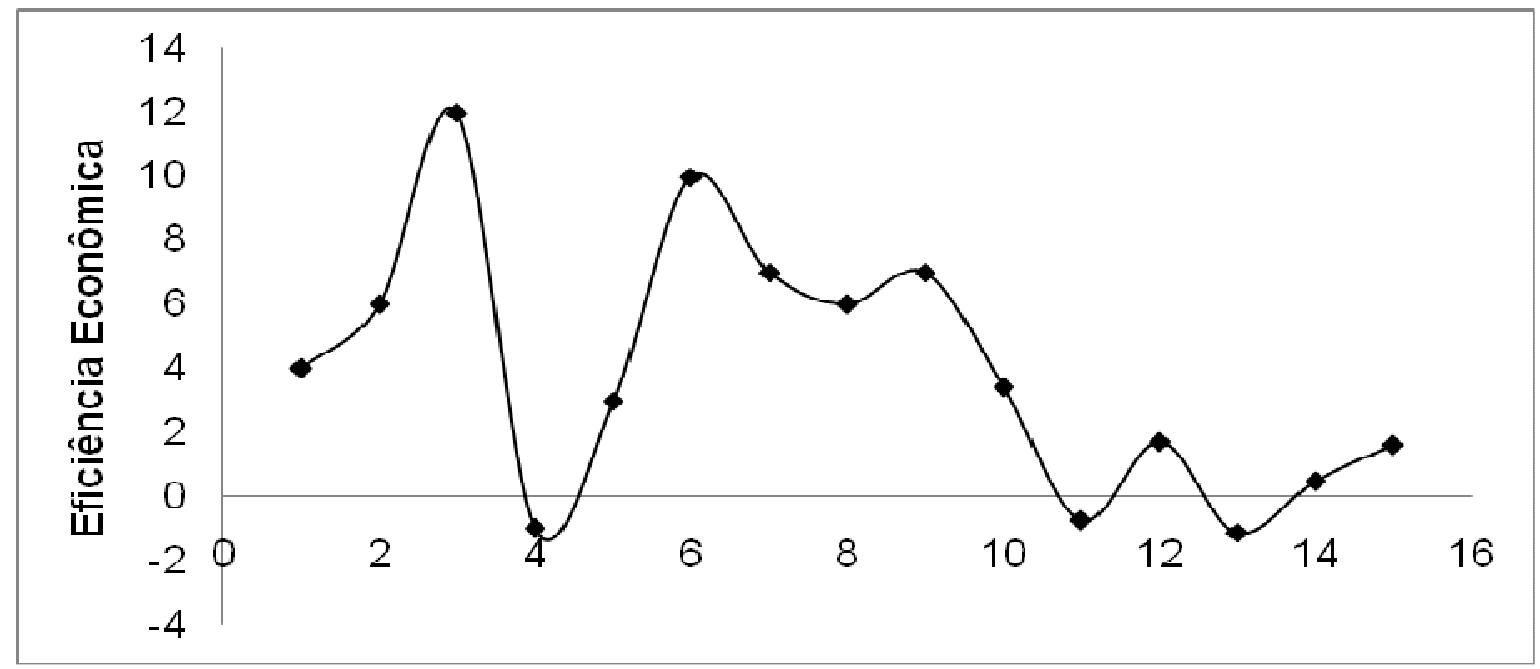

Figura 7: Distribuição da eficiência econômica dos tratamentos analisados em relação aos tratamentos controle.

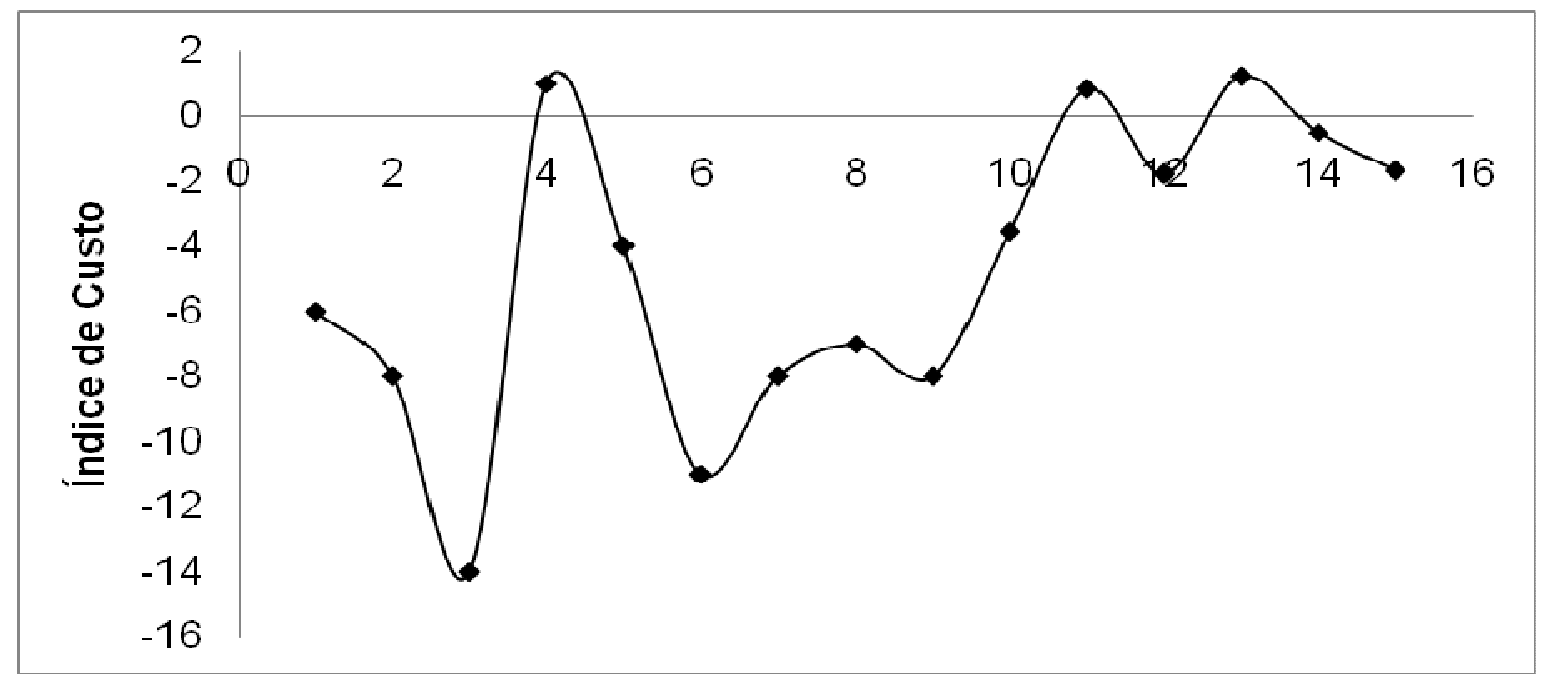

Figura 8: Distribuição do índice de custo dos tratamentos analisados em relação ao controle de cada experimento.

\section{Conclusão}

O método metanalítico foi considerado uma forma eficiente de analisar e ter uma visão global que permite avaliar como são as respostas dos experimentos com utilização do grão úmido na dieta dos animais, seja ruminantes ou monogástricos. No geral o uso do grão úmido teve na maioria 
TEODORO, A.L. et al. Grão úmido na alimentação animal: estudo metanalítico. PUBVET, Londrina, V. 6, N. 4, Ed. 191, Art. 1283, 2012.

dos experimentos efeitos positivos, no entanto, em algumas pesquisas os ganhos podem ser indiretos e estes não foram mensurados, além das condições individuais em que os ensaios experimentais foram desenvolvidos.

\section{Referências}

ALMEIDA JÚNIOR, G.A.; COSTA, C.; MONTEIRO, A.L.G.; GARCIA, C.A.; MUNARI, D.P.; NERES, M.A. Qualidade da carne de cordeiros criados em creep feeding com silagem de grãos úmidos de milho. Revista Brasileira de Zootecnia, v.33, n.4, p.1039-1047, 2004a.

ALMEIDA JÚNIOR, G.A.; COSTA, C.; MONTEIRO, A.L.G.; GARCIA, C.A.; MUNARI, D.P.; NERES, M.A. Desempenho, Características de Carcaça e Resultado Econômico de Cordeiros Criados em Creep Feeding com Silagem de Grãos Úmidos de Milho. Revista Brasileira de Zootecnia, v.33, n.4, p.1048-1059, 2004b.

ALMEIDA JÚNIOR, G.A.; COSTA, C.; CARVALHO, S.M.R.; PERSICHETTI JÚNIOR, P.; PANICHI, A. Desempenho de bezerros holandeses alimentados após o desaleitamento com silagem de grãos úmidos ou grãos secos de milho ou sorgo. Revista Brasileira de Zootecnia, v.37, n.1, p.148-156, 2008a.

ALMEIDA JÚNIOR, G.A.; COSTA, C.; CARVALHO, S.M.R.; PANICHI, A.; PERSICHETTI JÚNIOR, $P$. Desempenho de bezerros holandeses alimentados até o desaleitamento com silagem de grãos úmidos ou grãos secos de milho ou sorgo. Revista Brasileira de Zootecnia, v.37, n.1, p.140-147, 2008b.

ALMEIDA JÚNIOR, G.A.; COSTA, C.; CARVALHO, S.M.R.; PANICHI, A.; PERSICHETTI JÚNIOR, P. Características de carcaças e dos componentes não-carcaça de bezerros holandeses alimentados após o desaleitamento com silagem de grãos úmidos ou grãos secos de milho ou sorgo. Revista Brasileira de Zootecnia, v.37, n.1, p.157-163, 2008c.

ALMEIDA JÚNIOR, G.A.; COSTA, C.; CARVALHO, S.M.R.; PERSICHETTI JÚNIOR, P.; PANICHI, A. Composição físico-química de carcaças de bezerros holandeses alimentados após o desaleitamento com silagem de grãos úmidos ou grãos secos de milho ou sorgo. Revista Brasileira de Zootecnia, v.37, n.1, p.164-170, 2008d.

BARCELLOS, L.C.G.; FURLAN, A.C.; MURAKAMI, A.E.; SILVA. M.A.A.; SILVA, R.M. Avaliação nutricional da silagem de grãos úmidos de sorgo de alto ou de baixo conteúdo de tanino para frangos de corte. Revista Brasileira de Zootecnia, v.35, n.1, p.104-112, 2006.

BERNDT, A.; HENRIQUE, W.; LANNA, D.P.D.; LEME, P.R. e ALLEONI, G.F. Milho úmido, bagaço de cana e silagem de milho em dietas de alto teor de concentrado. Composição corporal e taxas de deposição dos tecidos. Revista Brasileira de Zootecnia, v.31, n.5, p.2105-2112, 2002.

FURLAN, A.C.; SCAPINELLO, C.; MOREIRA, I.; MARTINS, E.N. Avaliação nutricional da silagem de grãos úmidos de sorgo de baixo ou de alto conteúdo de tanino para coelhos em crescimento. Revista Brasileira de Zootecnia, v.35, n.3, p.775-784, 2006.

HENRIQUE, W.; BELTRAME FILHO, J.A.; LEME, P.R.; LANNA, D.P.D.; ALLEONI, G.F.; COUTINHO FILHO, J.L.V.; SAMPAIO, A.A.M. Avaliação da silagem de grãos de milho úmido com diferentes volumosos para tourinhos em terminação. Desempenho e características de carcaça. Revista Brasileira de Zootecnia, v.36, n.1, p.183-190, 2007.

IGARASI, M.S.; ARRIGONI, M.B.; HADLICH, J.C.; SILVEIRA.A.C.; MARTINS, C.L.; OLIVEIRA, H.N. Características de carcaça e parâmetros de qualidade de carne de bovinos jovens 
alimentados com grãos úmidos de milho ou sorgo. Revista Brasileira de Zootecnia, v.37, n.3, p.520-528, 2008.

IGARASI, M.S.; ARRIGONI, M.B.; SOUZA, A.A.; SILVEIRA.A.C.; MARTINS, C.L.; OLIVEIRA, H.N. Desempenho de bovinos jovens alimentados com dietas contendo grão úmido de milho ou sorgo. Revista Brasileira de Zootecnia, v.37, n.3, p.513-519, 2008.

LOVATTO, P.A.; LEHNEM, C.R.; ANDRETTA, I.; CARVALHO, A.D.; HAUSCHILD, L. Meta-análise em pesquisas científicas - enfoque em metodologias. Revista Brasileira de Zootecnia, v.36, suplemento especial, p.285-294, 2007.

LOVATTO, P.A.; WESCHENFELDER, V.A.; ROSSI, C.A.R.; LEHNEN, C.R.; ANDRETTA, I. Porcas lactantes alimentadas com dietas contendo silagem de grãos úmidos de milho e ácidos orgânicos. Ciência Rural, v.39, n.4, jul, 2009.

OLIVEIRA, K.; COSTA, C.; FAUSTINO, M.G.; GASQUE, V.S.; SANTOS, V.P.; LIMA, M.N.; NASCIMENTO FILHO, V.F.; ABDALLA, A.L. Trânsito gastrintestinal e digestibilidade aparente de nutrientes em eqüinos alimentados com dietas contendo grãos secos ou silagem de grãos úmidos de triticale. Revista Brasileira de Zootecnia, v.36, n.6, p.1799-1808, 2007.

OLIVEIRA, R.P.; FURLAN, A.C.; MOREIRA, I.; FRAGA, A.L.; BASTOS, A.O. Valor Nutritivo e Desempenho de Leitões Alimentados com Rações Contendo Silagem de Grãos Úmidos de Milho. Revista Brasileira de Zootecnia, v.33, n.1, p.146-156, 2004.

PASSINI, R.; RODRIGUES, P.H.M.; CASTRO, A.L.; SILVEIRA, A.C. Parâmetros de fermentação ruminal em bovinos alimentados com grãos de milho ou sorgo de alta umidade ensilados. Revista Brasileira de Zootecnia, v.32, n.5, p.1266-1274, 2003.

PATRICIO, V.M.I.; FURLAN, A.C.; MOREIRA, I.; MARTINS, E.N.; JOBIM, C.C.; COSTA, C. Avaliação nutricional da silagem de grãos úmidos de sorgo de alto ou de baixo conteúdo de taninos para leitões na fase de creche. Revista Brasileira de Zootecnia, v.35, n.4, p.14061415, 2006.

PUTRINO, S.M.; LEME, P.R.; SILVA, S.L.; ALLEONI, G.F.; LANNA, D.P.D.; GROSSKLAUS, C. Exigências líquidas de proteína e energia para ganho de peso de novilhos Nelore alimentados com dietas contendo grão de milho úmido e gordura protegida. Revista Brasileira de Zootecnia, v.35, n.1, p.301-308, 2006.

REIS, W.; JOBIM, C.C.; MACEDO, F.A.F.; MARTINS, E.N.; CECATO, U.; SILVEIRA, A. Desempenho de cordeiros terminados em confinamento, consumindo silagens de milho de grãos com alta umidade ou grãos de milho hidratados em substituição aos grãos de milho seco da dieta. Revista Brasileira de Zootecnia, v.30, n.2, p.596-603, 2001.

SANTOS, C.P.; FURTADO, C.E.; JOBIM, C.C.; FURLAN, A.C.; MUNDIM, C.A.; GRAÇA, E.P. Avaliação da silagem de grãos úmidos de milho na alimentação de eqüinos em crescimento: valor nutricional e desempenho. Revista Brasileira de Zootecnia, v.31, n.3, p.1214-1222, 2002.

SILVA, A.A.; MARQUES, B.M.F.P.P.; HAUSCHILD, L.; GARCIA, G.G.; LOVATTO, P.A. Digestibilidade e balanços metabólicos da silagem de grãos úmidos de milho para suínos. Ciência Rural, v.35, n.4, jul-ago, 2005.

SILVA, S.L.; LEME, P.R.; PUTRINO, S.M.; VALINOTE, A.C.; NOGUEIRA FILHO, J.C.M.; LANNA, D.P.D. Milho grão seco ou úmido com sais de cálcio de ácidos graxos para novilhos Nelore em confinamento. Revista Brasileira de Zootecnia, v.36, n.5, p.1426-1434, 2007.

ZOPOLLATTO, M.; DANIEL, J.L.P.; NUSSIO, L.G. Aditivos microbiológicos em silagens no Brasil: revisão dos aspectos da ensilagem e do desempenho de animais. Revista Brasileira de Zootecnia, v.38, suplemento especial, p.170-189, 2009. 